See discussions, stats, and author profiles for this publication at: https://www.researchgate.net/publication/341133756

\title{
Prospection of geo-resources for the building of social houses in Cuba
}

\section{Conference Paper · May 2020}

DOI: 10.5194/egusphere-egu2020-7309

\section{CITATIONS}

0

6 authors, including:

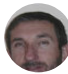

Domingo Alfonso Martín-Sánchez

Universidad Politécnica de Madrid

23 PUBLICATIONS 20 CITATIONS

SEE PROFILE

Leticia Presa Madrigal

Universidad Politécnica de Madrid

3 PUBLICATIONS OCITATIONS

SEE PROFILE
2. Jorge Costafreda

1. Centre for Plant Biotechnology and Genomics 33 PUBLICATIONS 46 CITATIONS

SEE PROFILE

Ana García-Laso

11 PUBLICATIONS 4 CITATIONS

SEE PROFILE

Some of the authors of this publication are also working on these related projects:

RES2+U Sección de Monitorización View project

Caracterización, aplicaciones y normalización de las zeolitas naturales de algunos países de lberoamérica View project 
EGU2020-7309

https://doi.org/10.5194/egusphere-egu2020-7309

EGU General Assembly 2020

(c) Author(s) 2020. This work is distributed under

the Creative Commons Attribution 4.0 License.

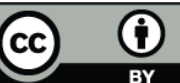

\section{Prospection of geo-resources for the building of social houses in Cuba}

Domingo Alfonso Martín Sánchez ${ }^{1}$, Jorge Luis Costafreda Mustelier ${ }^{2}$, Leticia Presa Madrigal ${ }^{3}$, Ana García Laso ${ }^{4}$, and Juan Antonio Rodríguez Rama ${ }^{5}$

'Universidad Politécnica de Madrid, Escuela Técnica Superior de Ingenieros de Minas y Energía, Madrid, Spain (domingoalfonso.martin@upm.es)

2Universidad Politécnica de Madrid, Escuela Técnica Superior de Ingenieros de Minas y Energía, Madrid, Spain (jorgeluis.costafreda@upm.es)

${ }^{3}$ Universidad Politécnica de Madrid, Escuela Técnica Superior de Ingenieros de Minas y Energía, Madrid, Spain (leticia.presa.madrigal@alumnos.upm.es)

${ }^{4}$ Universidad Politécnica de Madrid, Escuela Técnica Superior de Ingenieros de Minas y Energía, Madrid, Spain (ana.garcia.laso@alumnos.upm.es)

${ }^{5}$ Universidad Politécnica de Madrid, Escuela Técnica Superior de Ingenieros de Minas y Energía, Madrid, Spain

(jrodriguez@alumnos.upm.es)

The Spanish group of the IAPG has one of its strategic areas focused on development cooperation, in order to solve environmental, ethical and social problems related to the management of geological resources. One of the branches of this cooperation focuses on natural materials prospection which can be used as cheap additives in the construction process. As a result of this line, a cooperation project was carried out framed in the program of the Universidad Politécnica de Madrid (UPM) with Latin America, specifically with the University of Moa, province of Holguín (Cuba). This research aims to characterize the deposits of natural pozzolans in the northeastern region of Cuba, and determine their possible applications in the manufacture of cements and mortars for the construction of social housing in that region. The tasks contemplated in the development of this project are divided into two fundamental parts; the first one, which describes the field campaigns in situ in which geological survey and sampling work was carried out, with the assimilation of natural samples from the selected deposits, as well as samples of slag extracted from a steel plant. The second part refers to the laboratory campaign, in which a great variety of tests have been carried out to determine the suitability of the samples, among which are mentioned: X-ray diffraction, scanning electron microscopy, chemical analysis, pozzolanicity, granulometric test, specific surface, real density, freezing, mechanical resistance and determination of the speed of propagation of the ultrasound. After analyzing the results obtained, it is concluded that the samples studied have the properties and characteristics necessary for the manufacture of cements and mortars with pozzolanic characteristics, justifying, in this way, the manufacture of products with a moderate production cost and with the quality for the construction of social housing and infrastructure, so necessary in the study area. 